\title{
A FEIRA LIVRE DE IRARÁ: UMA ANÁLISE CULTURAL
}

\author{
Juliana Nogueira de Almeida ${ }^{1}$ \\ Fernanda Reis dos Santos ${ }^{2}$
}

\begin{abstract}
Resumo: O presente trabalho analisou a história da cidade de Irará para entender o surgimento e importância da sua feira livre. A partir desse entendimento, foi estudada a influência social da feira a partir dos conceitos de sociabilidade, identidade e cultura e como esses se aplicam no contexto vivido por feirantes e fregueses. Após toda essa abordagem, fez-se interessante pensar na feira livre de Irará como Patrimônio Cultural Imaterial, enquadrado no Livro de Registro dos Lugares, que são os que possuem sentido cultural para a população local onde são realizadas práticas variadas. A abordagem metodológica para a realização da pesquisa foi a qualitativa, buscando compreender as relações sociais da feira livre. Foram utilizadas bibliografias e fontes, tais quais entrevistas e questionários com feirantes e moradores de Irará, visitas locais, fotografias, jornais antigos, atas, além das documentações existentes tanto em acervos pessoais, quanto no Arquivo Público Municipal de Irará e na Biblioteca Municipal de Irará. Foram levantados dados relativos à percepção dos feirantes diante do tema cultura e identidade e predominantemente, eles diziam se sentir integrantes e formadores da cultura da cidade.
\end{abstract}

Palavras-chave: Feira Livre, Irará, Cultura, Patrimônio.

\section{THE FREE FAIR OF IRARÁ: A CULTURAL ANALYSIS}

\begin{abstract}
The present work analyzed the history of the city of Irará to understand the emergence and importance of its fair. Based on this understanding, the social influence of the fair was studied from the concepts of sociability, identity and culture and how these apply in the context lived by fairgrounds and customers. After all this approach, it was interesting to think of the free fair of Irará as Intangible Cultural Heritage, framed in the Book of Places Registry, which are those that have cultural meaning for the local population where various practices are performed. The methodological approach for conducting the research was qualitative, seeking to understand the social relations of the fair. Bibliographies and sources were used, such as interviews and questionnaires with traders and residents of Irará, local visits, photographs, old newspapers, minutes, in addition to existing documentation
\end{abstract}

\footnotetext{
${ }^{1}$ Graduanda em Arquitetura e Urbanismo - Centro Universitário Ruy Barbosa; Pesquisadora bolsista Programa de Iniciação Tecnológica e Científica (PICT). E-mail: juliananogueiraa.arq@gmail.com.

${ }^{2}$ Pesquisadora e Orientadora - Centro Universitário Ruy Barbosa. E-mail: fernandareisdossantos@gmail.com.
} 
both in personal collections, in the Municipal Public Archive of Irará and in the Municipal Library of Irará . Data were collected regarding the perception of the fairgrounds regarding the theme of culture and identity and predominantly, they said they felt they were members and formers of the city's culture.

Keywords: Free Fair, Irará, Culture, Heritage.

\section{Introdução}

O presente trabalho tem por objetivo analisar a Feira Livre da cidade de Irará como um espaço cultural. Para início dessa análise, foi feita uma contextualização histórica da cidade de Irará para entender como a feira se insere. Logo após, houve uma abordagem sobre espaço público - local onde as feiras livres ocorrem, conceituação e correlação com os temas supracitados. Baseado nessa correlação entre sociabilidade, identidade e cultura, infere- se o motivo pelo qual a feira livre é tão importante na cidade de Irará e porque é considerada uma influência social e não apenas econômica. É um tema de abordagem relevante porque a partir dessa análise, foi possível entender que a feira livre vai além das relações de compra e venda, pois possibilita interrelações humanas, sociais, culturais, identitárias e provocam a interação do indivíduo com o meio. Após o entendimento acerca de identidade, memória e cultura, o artigo visou motivar a valorização da Feira Livre de Irará como Patrimônio Cultural Imaterial.

Sendo assim, o trabalho tem o propósito de atribuir a real importância de uma feira livre sobre quem a frequenta e sobre a cidade onde ela se insere.

\section{Breve Histórico da cidade de Irará}

Irará é um município baiano centrado em uma zona de transição entre o recôncavo e o semi-árido do Nordeste (SANTOS, 2009, p. 4). Por volta do século XVI a região de Irará era habitada pelos índios Paiaiás que pertencem ao grupo dos Quiriris da grande nação dos Tapuias (SANTOS, 2009, p. 19). O nome desse município origina-se do Tupi e é uma alteração de "arará", uma espécie de formigas com asas brancas, cujo nome significa "nascida da luz do dia”, porque as formigas surgem na alvorada (SANTOS, 2009, p. 1). 
Inicialmente, com o nome de Purificação dos Campos, a vila começou a ser colonizada na segunda metade do século XVII com as entradas de Antônio Guedes Brito, mestre da casa da Ponte, que possuía muitas propriedades herdada da sua família. No mesmo contexto de concessão de terras, João Lobo Mesquita recebeu de Guedes Brito, uma grande área de terras, na qual passou a ter escravos, criação de gado e moradias e abrindo a “estrada de boiadas" para o sertão. Concedeu, a João Peixoto Viegas, em 1650, parte de suas terras situadas entre Jacuípe e água Fria, que abrangia a atual Irará (SANTOS, 2009, p. 29).

Nessa época, os indígenas eram encontrados em abundância na região da Purificação dos Campos e já haviam jesuítas com intuito de catequizá-los. Mas a partir do momento em que a intenção de João Peixoto Viegas era adentrar esse território e estender sua criação de gado, começaram a surgir conflitos entre jesuítas e curraleiros, pois estavam invadindo terras inicialmente indígenas, para colocar currais. (SANTOS, 2009, p. 31).

Os jesuítas foram expulsos da colônia por volta de 1759, decorrente de disputas de poder e privilégios e como consequência, aumentaram as buscas por terras no sertão da Bahia. Dessa forma, as terras de Irará iam ganhando demarcações onde eram implantadas fazendas e currais de gado (SANTOS, 2009, p. 33). Segundo Jucélia Bispo (2009, p. 1).

A Colonização só se consolidou, de fato, nos solos do atual município de Irará a partir do avanço da pecuária no século XVIII, quando ocorreu a instalação de currais de gado em todo o sertão baiano, tais como os do capitãomor, Antônio Homem de Afonseca e o de Diogo Alves Campos.

Em um dos currais existentes, onde hoje se encontra a Praça da Purificação, foi construída, pelo pai do Padre Antônio Correia, uma capela que pertencia à freguesia de São José das Itapororocas e que funcionou como matriz até a década de 1930 (SANTANA, 1988, p. 28), quando foi demolida na gestão do então prefeito Elísio Santana (SANTOS, 2009, p. 22).

Segundo Alberto Santana (SANTANA, 1988, p. 28), o crescimento do arraial de Purificação se deu com a abertura da estrada que ligava o porto de Cachoeira com a Vila de Água Fria, encontrando-se com a estrada de Pindá que se interligava com outros estados. Por essa estrada eram transportados 
gados e fumo de toda a região para o porto de Cachoeira passando por Feira de Santana.

O município pertenceu a Feira de Santana até 1842. Pela Lei no173 desse mesmo ano, o município de Água Fria foi extinto e Irará passou a ser constituído pelos territórios da antiga Vila de Água Fria, freguesias de Nossa Senhora da Purificação e do Sagrado Coração de Bom Jesus de Pedrão, pertencente à Vila de Feira de Santana (SANTANA, 1988, p. 29). A vila da Purificação foi então elevada à condição de cidade pela lei estadual de 08.08.1895 com a denominação de Irará (SANTOS, 2009, p. 3).

\subsection{Desenvolvimento de Irará através das estradas}

O florescimento do arraial da Purificação se deu com a abertura da estrada que ligava o porto de Cachoeira com a Vila de água Fria, encontrando-se com a estrada de Pindá, que ia para as minas de Jacobina, Rio São Francisco e Piauí. [...] essa estrada não foi apenas de penetração, mas também de caráter econômico, pois por ela descia o gado e se transportava o fumo de toda a região para o porto de Cachoeira, com pousada no sítio onde hoje é Feira de Santana. (SANTANA, 1988, p. 28).

A construção de estradas que contribuía diretamente para o crescimento comercial e consequentemente econômico das cidades naquela região entre Feira de Santana e Irará, se evidenciava na década de 1920.

A construção e o desenvolvimento de estradas de rodagem representaram um dos símbolos máximos da Feira de Santana moderna e progressista. Esse sistema viário propiciou a transformação da cidade em uma espécie de entroncamento ou encruzilhada delineando todo um ideário de modernidade, que antes de qualquer coisa, fora responsável por proporcionar maiores contatos, volume e rapidez no comércio. Dessa forma, essas estradas podem ser tomadas como veto de construção imagética de uma nova ordem que a partir dos finais da década de 1920, ganhara cada vez mais espaço e estímulo. (LIMA, 2012, p. 44)

Quanto ao crescimento da área urbana e do comércio de Irará, podemos fazer um elo ao crescimento de Feira de Santana. Não no sentido de equiparar seus respectivos desenvolvimentos, mas à medida que o comércio 
de Feira de Santana, crescia e eram criadas estradas de rodagem para deslocamento de mercadorias, Irará que é um município próximo, também se expandia aos poucos. Sobre o crescimento de Feira de Santana, Karine (DAMASCENO 2012, p. 16, apud, POPPINO, 1968), cita:

Desde sua origem, o comércio de gado constituiu-se como a principal atividade econômica do município, ao mesmo tempo em que uma grande variedade de produtos de origem agrícola, como farinha de mandioca, feijão, milho, dentre outros fundamentais na alimentação da população local, eram vendidos na feira livre, abastecendo tanto os moradores locais quanto de outras regiões do interior do estado e da capital.

Junto a esse progresso das rodovias e consolidação de Feira de Santana na década de 1920, Irará se desenvolvia e passou então a ser um centro comercial da região através da feira livre.

Apesar da modesta dimensão da sua zona urbana, quando compreendia um máximo de quatro ou cinco ruas e duas praças, Irará era um centro comercial da região, respaldado pelo seu comércio, pela agricultura fumageira e principalmente pela feira-livre que já naquela época acontecia aos sábados. A feira, desde então, era o ápice das relações mercantis entre a sede, os seus distritos Água Fria, Bento Simões, Ouriçangas, Pedrão e Quaresma (hoje Santanópolis) - e outros municípios como Feira de Santana e Alagoinhas. Depois da década de 1960, todos aqueles distritos, à exceção de Bento Simões, foram emancipados de Irará (MARTINS, 2007, p. 9).

\section{O desenvolvimento da Feira Livre de Irará}

A construção do Mercado Municipal de Irará foi iniciada em 1921, pelo intendente Coronel Elpídio Nogueira (PINHO, 2008, p. 25). Na atual praça da Purificação dos Campos com a fachada frontal voltada para o fundo da Igreja que se localizava no centro da praça (PORTELA, 2017) ${ }^{3}$. A fase de construção durou aproximadamente uma década, até que em 1930, quando a cidade estava sob administração de Elísio Santana, foram realizados alguns

\footnotetext{
${ }^{3}$ Entrevista concedida a autora por Deraldo Portela. [set.2017].
} 
acabamentos como colocação de piso, rebocos, portas de ferro e reparos finais. Em 1932, o Mercado foi inaugurado e os feirantes que vendiam seus produtos ao redor da Igreja, foram deslocados para o interior do mesmo. (PINHO, 2008, p. 25).

Segundo relatos de Deraldo Portela, desde as décadas de 1920 a 1930 a feira era realizada aos sábados e os feirantes em geral se situavam ao lado direito da Igreja, até que começou a se expandir nos arredores, mas até então, era realizada apenas na praça (PORTELA, 2017).

A Igreja de Nossa Senhora da Purificação, provavelmente construída entre os séculos XVIII e XIX , foi demolida entre 1936 e 1937 (PINHO, 2008, p. 26) e de acordo com Professora Miriam Benevides, tal fato ocorreu por iniciativa dos comerciantes que tinham lojas na atual praça da Purificação e diziam que a Igreja ali edificada, prejudicava o comércio (BENEVIDES, 2017)5.

Ao analisarmos a importância das praças nas cidades, percebemos que são espaços públicos aos quais são destinados usos, em sua maioria, específicos que geralmente desempenham um papel na vida dos indivíduos da cidade. Existem praças onde se realizam funções de lazer, administrativas, comerciais e mistas e podemos observar que tais funções já eram utilizadas desde o período medieval.
Espaço livre, lugar onde se desenvolvem os principais acontecimentos coletivos da vida cotidiana [...] a configuração da praça medieval definiu-se pelo contraste do vazio com a densa paisagem, estruturando uma diversidade de espaços: praças de mercado, praça da igreja, praça cívica, praça de entrada, praça central, ou mesmo conjunto de praças (CALDEIRA, 2007, p. 23).

A atual Praça da Purificação, na qual ocorre a feira livre e grande parte do comércio de Irará, pode se denominar como praça de mercado. Analisando a história da cidade, pode-se dizer que a praça citada contribui muito para o desenvolvimento da cidade de Irará e por isso tem grande relevância histórica.

\footnotetext{
${ }^{4}$ Data estipulada entre o ano de expulsão dos Jesuitas da Vila da Purificação (por volta de 1759) e o ano de criação da freguesia de Nossa Senhora da Purificação, pelo Decreto no 153, de 28/02/1842.

${ }^{5}$ Entrevista concedida a autora por Miriam Benevides. [set.2017].
} 


\section{Feira livre: espaço de cultura, identidade e sociabilidade}

As feiras livres possuem uma influência social muito forte. Isso porque além de serem frequentes no cotidiano da cidade e trazerem consigo características que envolvem quem as frequenta, seja por cheiros, hábitos, diálogos ou métodos de compra, é um evento que abrange uma grande parcela da população, pois é realizado em espaços públicos.

A partir desse ponto, torna-se imprescindível discorrer sobre a relação entre o espaço público e a sociabilidade e porque esta, é um tema tão discutido quando se trata de feira livre.

Como espaço público, podemos entender, conforme a afirmação de Felipe Silveira, que "é resultado de uma construção social ligada à necessidade de sociabilidade entre os homens, e nesse sentido é produto" (SILVEIRA, 2018, p. 16). Para embasar um pouco mais essa conceituação, Leite afirma:

Nesse caso, entende-se que uma noção de espaço público requer, para qualificar como públicos determinados espaços urbanos da vida contemporânea, uma inserção conceitual de mão dupla entre espaço e sociabilidade pública. Implica, portanto, relacionar, dois processos interdependentes, que concorrem simultaneamente para uma única direção: a construção social do espaço, enquanto produto e produtor de práticas sociais; e a construção espacial da sociabilidade pública, enquanto produto e produtor das espacialidades da vida social (SILVEIRA, 2018, p. 15, apud, LEITE, 2004).

Analisando tais conceitos, podemos concluir que o espaço é definido como público, não apenas por ser de uso comum, e sim por permitir a construção de uma sociabilidade, que por sua vez produz as espacialidades da esfera pública. Ou seja, esses dois vieses se interdependem como num ciclo.

Por sociabilidade, de acordo com Yasminie, podemos entender que é "uma interação que não resulta de necessidades ou interesses específicos, mas que preserva a satisfação do estar socializado que acompanha o processo de interação" (CERQUEIRA, 2013, p. 60). Logo, sociabilidade é a capacidade do indivíduo se relacionar com o meio. 
Entretanto, há uma definição formulada por Tönnies ${ }^{6}$, chamada sociabilidade mercantil, que é caracterizada pelos "efeitos do comércio como ocupação econômica de maior peso e visibilidade sociocultural" (BRANCALEONE, 2018, p. 101).

O dinheiro como equivalente geral, é um elemento importante na estruturação dessa sociabilidade societária urbana, pois aprofunda um estado de isonomia social sem precedentes, podendo ser tudo e todos (pessoas, lugares, objetos, posições de prestígio) por ele cambiáveis (BRANCALEONE, 2018, p. 101).

As duas definições de sociabilidade supracitadas, englobam o contexto da feira livre. Isso porque, além de ser mercantil, pois atende à população de forma capitalista, com suas relações de compra e venda; não exclui o caráter da sociabilidade por interação, na qual o indivíduo se relaciona com o meio e nele se identifica.

As feiras livres são caracterizadas tanto como centros de mercado, modalidade de comércio varejista, ao ar livre, de utilidade pública ao fazer abastecimento alimentar das cidades, quanto se constituem em espaços de socialização e de manutenção cultural. (ANTÉRIO, 2012, p. 924).

A interação social é facilmente identificada na relação entre vendedores e fregueses. Muitas dessas relações, por serem bastante frequentes, passam a se estabelecer por meio da amizade, do costume e não mais pelo simples motivo de compra.

A feira livre tem esse caráter diversificado, onde circulam por ela vendedores, compradores, transeuntes, personagens e outros participantes variados. Estas pessoas circulam muito, examinam, pechincham ou simplesmente estão à procura do que desejam, sendo que outras já tem seus feirantes preferidos, conhecem estes de longa data e às vezes criam laços de afetividade mais profundos tornando-se mais amigos do que fregueses. (BOECHAT, não datado, p. 07).

\footnotetext{
6 "Um dos pioneiros da ciência social alemã, da última metade do século XIX e início do XX." - trecho retirado do artigo: Comunidade, sociedade e sociabilidade: revisitando Ferdinand Tönnies.
} 
Segundo Seu André, bananeiro da feira livre de Irará, seus fregueses não são apenas fregueses, são amigos. Ele diz que não vende apenas por vender, vende porque ama e ele procura oferecer o melhor atendimento a seus clientes, para que esses fiquem satisfeitos e voltem todo o sábado. Em sua maioria, os clientes de Seu André são fixos há anos e ainda há confiança de deixar o produto a pagar em outro dia.

De acordo com Camila Guimarães,

Desenvolvem-se e cultivam-se, nesse espaço, relações de confiança, troca e amizade. Não existe apenas a venda. Há confiança tanto no valor e qualidade dos produtos comercializados, quanto nos vendedores e pessoas conhecidas encontradas no local. Ocorrem fofocas, lembranças, preservação dos costumes e da rotina (já que ocorrem em dias determinados) e mantêm-se hábitos e as relações com a comunidade. (GUIMARÃES, 2010, p. 12).

Seu André ainda relata que vender na Feira Livre de Irará é costume da família, oriunda do município de Coração de Maria, mas que nunca vendeu no município natal. Ele relatou que desde os dez anos se deslocava para a cidade de Irará aos sábados, junto com seu pai e seus irmãos para vender produtos variados, mas já como principal produto, a banana. No diálogo com ele, a sociabilidade e principalmente a identidade cultural se evidenciam quando ele diz "Se eu não vier para a Feira de Irará, pra mim não é dia de sábado." (SANTOS, 2017)

Nesse contexto, podemos identificar que além da função social que a feira livre exerce, há uma grande influência identitária e cultural, que concomitantemente, relacionam-se, evidenciando o caráter intrínseco na formação do arcabouço cultural de uma cidade.

No geral, o evento pode se apresentar como um momento de rever conhecidos, como uma mistura de lazer e cotidiano - ainda que estejam sendo realizadas atividades rotineiras, necessárias, é uma oportunidade de viver algo diferente, uma comemoração dentro do dia a dia. Um local lúdico e transgressor. Um ambiente alegre e unido, um espaço de liberação através da interação social - por

${ }^{7}$ Entrevista concedida a autora por André Santos. [set.2017]. 
meio de dança, riso, conversas, ditos populares, músicas etc. (GUIMARÃES, 2010, p. 11).

Tomando como referência a concepção de identidade de acordo com a noção de sujeito sociológico, na qual o indivíduo tem identidade socialmente construída em constante mudança, podemos dizer que:

A identidade é formada na "interação" entre o eu e a sociedade. O sujeito ainda tem um núcleo ou essência interior que é o "eu real", mas este é formado e modificado num diálogo contínuo com os mundos culturais "exteriores" e as identidades que esses mundos oferecem. (HALL, não datado, p. 11).

E ainda, segundo mesmo autor,

A identidade torna-se uma "celebração móvel": formada e transformada continuamente em relação às formas pelas quais somos representados ou interpelados nos sistemas culturais que nos rodeiam. É definida historicamente, e não biologicamente (HALL, não datado, p. 13).

Podemos afirmar então, que um indivíduo sociável, tem a capacidade de formação de identidade de acordo com o que vive, vê ou elege melhor para si. Logo, podemos compreender identidade como a capacidade de construção de pessoa, a partir de estímulos externos e graus de influência que tais estímulos exercem sobre o indivíduo, pois nem tudo o que nos é oferecido socialmente, nos interessa absorver para nos constituir.

Espaços e costumes são dois, dos diversos estímulos externos que nos são apresentados e que contribuem diretamente na formação da identidade social e é o caso das feiras livres. Um evento cotidiano onde há grande fusão de costumes, vivências e histórias, "um espaço com muita especialidade, cheio de sons, movimentos, coloridos e personagens, que interagem com o seu histórico e suas relações de identidade" (BOECHAT, não datado, p. 1).

A feira livre altera toda a dinâmica urbana e social nos dias em que ocorre, isso porque pode ser vista como um evento capaz de movimentar diversos grupos para diversos fins que no final, se interdependem. Não pode ser vista apenas como uma atividade comercial, e sim como espaços de manifestação de identidade. Segundo Patrícia Boechat, “A feira se configura mais que um ponto comercial da agricultura familiar, pois nesse meio 
circulam bens, culturas e pessoas, sendo uma partilha entre economia e cultura." (BOECHAT, não datado, p. 8).

Foram traçadas todas as definições e correlações entre espaço público, sociabilidade, identidade e feira livre, para podermos entender qual a relação com a cultura. Não há unanimidade estabelecida quanto ao seu conceito, Matta distingue dois deles, um é utilizado para descriminar grupos:

Cultura aqui é equivalente a um volume de leituras, a controle de informações, a títulos universitários e chega até mesmo a ser confundida com inteligência, como se a habilidade para realizar certas operações mentais e lógicas (que definem de fato a inteligência) fosse algo a ser medido ou arbitrado pelo número de livros que uma pessoa leu, as línguas que pode falar, ou os quadros e pintores que pode, de memória enumerar. (ROCHA, 2005, p. 11, apud, DA MATTA, 1994)

Pensar cultura de forma tão elitista, é segregar grande parcela da população brasileira que não usufrui de tais recursos. Seria então dizer, que indivíduos que não frequentaram escolas ou que não tenham título universitário, são sem cultura. O que não é verdade! Nesse caso, o conceito de cultura está relacionado à educação ou sofisticação, segundo o qual "cultura significa nível social e educacional, sendo atribuída àqueles considerados letrados; apreciadores e conhecedores das artes, ciências e outros campos do conhecimento." (ROCHA, 2005, p. 11).

Já o outro conceito do mesmo autor, pensado antropologicamente, diz que:

Para nós, "cultura" não é simplesmente um referente que marca uma hierarquia de "civilização", mas a maneira de viver total de um grupo, sociedade, país ou pessoa. Cultura é, em Antropologia Social e Sociologia, um mapa, um receituário, um código através do qual as pessoas de um dado grupo pensam, classificam, estudam e modificam o mundo e a si mesmas (ROCHA, 2005).

Cultura seria então um elemento que nos torna pertencentes dentro de determinada sociedade e exclusos de qualquer outra da qual não nos identificamos? Dessa forma, somos então, rotulados e identificados como aculturais dentro de um grupo do qual não fazemos parte. É portanto, uma ação da sociedade sobre nossos hábitos, maneiras, o que, nesse caso não deixa 
de ser uma verdade, mas para nossa análise, vamos considerar que vá além disso.

A cultura é a própria identidade nascida na história, que ao mesmo tempo nos singulariza e nos torna eternos. É índice e reconhecimento da diversidade. É o terreno privilegiado da criação, da transgressão, do diálogo, da crítica, do conflito da diferença e do entendimento (BORGES, 2017, p. 20, apud, CAMPOMORI, 2008).

Temos ainda, uma outra definição:

Conjunto de rasgos distintivos materiais e espirituais, intelectuais e afetivos, que caracterizam uma sociedade ou grupo social. Ela engloba artes e letras, modos de vida, direitos fundamentais ao ser humano, sistemas de valores, tradições e crenças (ICOMOS, 1985).

É notório que muitas são as definições e todas se convergem, o que torna seu conceito bastante complexo, mas cabe evidenciar que essas duas últimas definições, um pouco mais próximas da realidade da feira livre já nos dá o entendimento de que cultura não é privilégio de um grupo elitista que domina o saber, ou um rótulo que nos exclui de grupos diversos. Cultura é pra ser pensado de forma abrangente, como elemento que é construído através da história e de influências externas - a exemplo do contato com outras culturas - e por isso, está em constante mudança e não pode ser mensurada, nem tão pouco enaltecida como superior se comparada a qualquer outra. Engloba modos de vida, hierarquia dos saberes, crenças, tradições e modos de fazer, que constitui a identidade do indivíduo e permite que o essencial seja disseminado a outras gerações, mesmo que sua estrutura original se adeque ao tempo para assim poder sobreviver.

A partir das conceituações, podemos afirmar que as feiras livres são disseminadoras de cultura e proporcionam relações de identidade. Sobre isso Guimarães afirma, "as feiras livres são esses espaços de manutenção cultural porque elas sustentam interações simbólicas e costumes, fazendo interagir os valores culturais de um povo e preservando características passadas por gerações" (GUIMARÃES, 2010, p. 12).

Em suma, podemos afirmar que a feira livre é um espaço cultural, diversificado, no qual não predominam apenas as relações de compra, e sim, 
relações sociais, indentitárias e culturais que em geral se integram com às características do lugar onde está instalada, nesse caso, Irará.

\section{A Feira Livre de Irará: patrimônio cultural}

A partir de todo o entendimento acerca do caráter cultural das feiras livres, podemos entender porque elas podem ser consideradas patrimônios culturais e porque é importante serem reconhecidas e preservadas. Mas para isso, abordaremos um pouco sobre memória.

Por memória podemos compreender, experiências do passado, que perduram no presente a partir do seu grau de importância e compõem a identidade de um indivíduo ou grupo. A memória é designada coletiva, quando é construída a partir de experiências compartilhadas e mesmo não sendo vividas por quem as ouviu, se tornam parte da sua história.

Sendo assim, diante dos relatos dos feirantes, a feira livre de Irará, é para eles, umlugar de memória.

A definição de lugares de memória, de Pierre Nora, é válido dizer que nos arquivos, monumentos, memoriais e prédios históricos da cidade encontra-se não a memória de um grupo, cidade ou nação, mas sim uma determinada memória que foi construída pelos atores sociais daquele grupo, cidade ou nação, e que adquiriu legitimação ao longo dos anos (BIAZZETTO, 2013, p. 534).

Como foi possível observar, no trecho supracitado, a definição de lugar de memória se restringe a lugares edificados e materiais. Essa era a restrição para que Patrimônios Culturais fossem reconhecidos até que na Constituição de 1988, os Patrimônios Imateriais começaram a ser considerados. Como definição deste, temos: “O patrimônio imaterial é transmitido de geração a geração, constantemente recriado pelas comunidades e grupos em função de seu ambiente, de sua interação com a natureza e de sua história, gerando um sentimento de identidade e continuidade [...]". (IPHAN)

É nessa definição que se enquadram as feiras livres. Para atender de maneira mais específica e adequada, o Instituto do Patrimônio Histórico e Artístico Nacional - IPHAN, o Registro de Bens Culturais de Natureza Imaterial e, para reuni-los de acordo com categorias, os bens registrados são inscritos em um dos quatro Livros de Registro. São eles: Livro de Registro dos 
Saberes, Livro de Registro das Celebrações, Livro de Registro das formas de Expressão e Livro de Registro dos Lugares. (IPHAN).

Esse último é a categoria na qual a feira livre se enquadra. De acordo com o IPHAN,

Nele são inscritos os mercados, feiras, santuários e praças onde se concentram e/ou se reproduzem práticas culturais coletivas. Os lugares são aqueles que possuem sentido cultural diferenciado para a população local, onde são realizadas práticas e atividades de natureza variada [...]. (IPHAN)

Importante ressaltar que quando o bem é reconhecido, passa a ser salvaguardado pelo IPHAN que, por meio de instrumentos e ações, objetiva a manutenção e preservação dos mesmos.

De acordo com a lista de Bens Registrados do IPHAN, no Brasil tem duas feiras reconhecidas como Patrimônio Imaterial, a Feira de Caruaru em Pernambuco, registrada em 2006 e a Feira de Campina Grande na Paraíba, registrada em 2017. (IPHAN)

Um fato interessante sobre esta última feira e que poderia ser aplicado na feira de Irará, é que o espaço ocupado pela mesma, passou a ser área de interesse para requalificação urbana que seriam conduzidas com auxílio de ações de salvaguarda.

Como a Feira de Irará se estende por várias praças e ruas, seria interessante que houvesse possibilidade de execução de projetos de requalificação que prevejam infraestrutura, no que diz respeito a equipamentos urbanos, barracas de venda e organização espacial. Mas para isso, é importante sempre priorizar as necessidades dos feirantes e usuários do local.

Para que os instrumentos de salvaguarda tenham mais eficácia, o Programa Nacional do patrimônio Imaterial (PNPI) apoia iniciativas e práticas de preservação desenvolvidas pela sociedade. Essas iniciativas entram no âmbito da Educação Patrimonial que visa a participação da sociedade nas práticas de salvaguarda do bem, para que o processo de proteção seja constante e a população aja de forma consciente no mesmo.

Em suma, é importante que a população iraraense reconheça a feira da cidade de Irará como parte da sua cultura e exerça um papel atuante diante da possibilidade de reconhecimento da mesma. 


\section{Referências}

ANTÉRIO, Djavan; SILVA, Pierre Normando da. Relação Sociocultural dos Brinquedos Artesanais Vendidos em Feiras Livres. Educação \& Realidade, v.37, n.3. Porto Alegre, 2012.

BIAZZETTO, Giovanni. Educação patrimonial, patrimônio e memória: Conceitos construtores de cidadania e identidade. Revista Latino-Americana de História, vol.02, no 06. [S.L] 2013.

BOECHAT, Patrícia Tereza; SANTOS, Jaqueline Lima. Feira Livre: Dinâmicas Espaciais e Relações Identitárias. Salvador, não datado.

ALEONE, Cássio. Comunidade, sociedade e sociabilidade: revisitando Ferdinand Tönnies. Revista de Ciências Sociais, v.39. n.1. 2018.

CALDEIRA, Júnia Marques. A Praça Brasileira - Trajetória de um espaço Urbano: Origem e modernidade. Campinas, 2007.

CAMPOMORI, Maurício José. O que é avançado na cultura? Belo Horizonte, 2008. In: BORGES, Isley. Espaço, cultura e religião: um olhar para o neopentecostalismo underground. Ituiutaba, 2017.

CERQUEIRA, Yasminie Midlej. Espaço Público e Sociabilidade Urbana: apropriações e significados dos espaços públicos na cidade contemporânea.

CONFERÊNCIA MUNDIAL SOBRE AS POLÍTICAS CULTURAIS. ICOMOS Conselho internacional de Monumentos e Sítios. 1985.

DAMASCENO, Karine Teixeira. A Invisibilidade das Mulheres Negras na Documentação Oficial - Feira de Santana, 1890-1920. Revista de História da África e de Estudos da Diáspora Africana. Ano V, no IX, julho/2012.

DA MATTA, Roberto. O que faz Brasil, Brasil? Rio de Janeiro: Rocco, 1994. In: ROCHA, Anna Flávia. Correspondentes Internacionais: um diálogo entre culturas. Juiz de Fora, 2005.

GUIMARÃES, Camila Aude. A Feira Livre na Celebração da Cultura Popular. São Paulo, 2010.

HALL, Stuart. A Identidade Cultura da pós-modernidade. DP\&A Editora, 10. edição. Não datado.

INSTITUTO DO PATRIMÔNIO HISTÓRICO E ARTÍSTICO NACIONAL (IPHAN). Bens Imateriais Registrados e Área de Abrangência. [S.L], 2017. Disponível em: http://portal.iphan.gov.br/uploads/ckfinder/arquivos/Lista_Bens_Registrad os_por_estad o_2017.pdf

INSTITUTO DO PATRIMÔNIO HISTÓRICO E ARTÍSTICO NACIONAL (IPHAN). Feira de Campina Grande (PB) recebe título de Patrimônio Cultural do Br. [S.L], 2017. Disponível em: 
http://portal.iphan.gov.br/pb/noticias/detalhes/4689/feira-de- campinagrande-pb-recebe-titulo-de-patrimonio-cultural-do-brasil.

INSTITUTO DO PATRIMÔNIO HISTÓRICO E ARTÍSTICO NACIONAL (IPHAN). Livros de Registro. [S.L], não datado. Disponível em: http://portal.iphan.gov.br/pagina/detalhes/122.

INSTITUTO DO PATRIMÔNIO HISTÓRICO E ARTÍSTICO NACIONAL (IPHAN). Patrimônio Imaterial. [S.L], não datado. Disponível em: http://portal.iphan.gov.br/pagina/detalhes/234.

INSTITUTO DO PATRIMÔNIO HISTÓRICO E ARTÍSTICO NACIONAL (IPHAN). Programa Nacional do patrimônio Imaterial (PNPI). [S.L], 2017. Disponível em: http://portal.iphan.gov.br/pagina/detalhes/761/.

INSTITUTO DO PATRIMÔNIO HISTÓRICO E ARTÍSTICO NACIONAL (IPHAN). Registro de Bens Culturais de Natureza Imaterial. [S.L], não datado. Disponível em: http://portal.iphan.gov.br/pagina/detalhes/687.

LEITE, R.P. Contra-usos da cidade: lugares e espaço público na experiência urbana contemporânea. Campinas: UNICAMP: Aracajú: UFS, 2004. In: SILVEIRA, Felipe. O Espaço Público Contemporâneo: a complexidade vista através de parques urbanos de Porto Alegre. Porto Alegre, 2018.

LIMA, Carlos Alberto. Das luzes aos becos: Retratos da Rua do Meio na Feira Moderna. (1950-1967). In: CERQUEIRA, Aline Aguiar. Diversões e Civilidade na “Princesa do Sertão" (1919-1946) - Feira de Santana. Feira de Santana, 2012.

MARTINS, Marcos Roberto. Aristeu Nogueira: a Militância Política e Cultural de um Comunista. Salvador, 2007.

PINHO, Emerson Nogueira. A Construção: Histórias de Mestre Januário. Irará, 2008.

ROCHA, Anna Flávia. Correspondentes Internacionais: um diálogo entre culturas. Juiz de Fora, 2005.

SANTANA, Alberto Pereira de. Irará 88. Prefeitura Municipal de Irará, 1988. SANTOS, Jucélia Bispo dos. Colonização do Sertão da Bahia e Formação de Quilombos em Irará. Revista África e Africanidades - ano 2 - n. $7_{-}^{-}$ Novembro. 2009.

SANTOS, Jucélia Bispo dos. Etnicidade e Memória entre Quilombolas em Irará - Bahia. Salvador, 2008.

SANTOS, Jucélia Bispo dos. Indios Paiaiás e Negros aldeados: um projeto de Fricção Interétnica. Patrimônio: Lazer \& Turismo, v. 6, n. 7, jul.-ago.-set./2009.

SILVEIRA, Felipe. O Espaço Público Contemporâneo: a complexidade vista através de parques urbanos de Porto Alegre. Porto Alegre, 2018. 
A FEIRA LIVRE DE IRARÁ: UMA ANÁLISE CULTURAL

\section{Fontes}

BENEVIDES, Miriam. Memórias da Feira Livre de Irará: depoimento [set.2017]. entrevistadora autora. Irará, 2017.

PORTELA, Deraldo. Memórias da Feira de Irará: depoimento [set.2017]. Entrevistadora autora. Irará, 2017.

SANTOS, André. Vivências na Feira de Irará: depoimento [set.2017]. Entrevistadora a autora. Irará, 2017.

Recebido em 29 de abril de 2019.

Aceito em 30 de maio de 2019. 